\title{
ONE INEQUALITY FOR CONFORMAL MAPPINGS OF SPHERICAL DOMAINS
}

\author{
LUDMILA BOURCHTEIN AND ANDREI BOURCHTEIN
}

Abstract. We provide an evaluation of variations of the mapping factor for conic mappings from a sphere to a plane. The proved inequality allows to compare the variation coefficients of conic, cylindrical and stereographic projections. Obtained inequality chain for variation coefficients can be used to generate more computationally efficient numerical grids.

Mathematics subject classification (2000): 26D07, 30C20, 65M50.

Key words and phrases: function inequalities, conformal mappings, grid generation.

\section{REFERENCES}

[1] A. Bourchtein, L. Bourchtein, Comparative analysis of conformal mappings used in limited area models of numerical weather prediction, Mon. Wea. Rew., 131, (2003), 1759-1768.

[2] P. CouRTIER, J. F. GELEYN, A global numerical weather prediction model with variable resolution: application to the shallow water equations, Quart. J. Royal Met. Soc, 114, (1988), 1321-1346.

[3] H. R. GLAHN, Characteristics of map projections and implications for AWIPS-90, TDL Office Note 88-5, (National Weather Service, NOAA, 1988).

[4] I. S. GRADSHTEYN, I. M. RYZHIK, Tables of integrals, series and products (Academic Press, 1994).

[5] W. J. SAUCIER, Principles of meteorological analysis, (The University of Chicago Press, 1962).

[6] J. F. ThOMPSON, Z. U. A. WARSI AND C. W. MASTin, Numerical grid generation, (North-Holland, 1985).

[7] D. L. WILLIAMSON, Difference approximations for numerical weather prediction over a sphere, (GARP Publ. Ser., 17, (II), 1979). 